\title{
Do Plant InVAsions Change the Effects of FiRE on ANImals?
}

\author{
Robert J. Steidl* and Andrea R. Litt ${ }^{1}$ \\ School of Natural Resources, University of Arizona, \\ 325 Biological Sciences East, Tucson, Arizona 85721, USA \\ *Corresponding author: Tel.: 001-520-626-3164; e-mail: steidl@ag.arizona.edu
}

\begin{abstract}
Fire and invasions by nonnative plants can change the structure and function of ecosystems, and independent effects of each of these processes have been well studied. When fire is restored to areas where it has been excluded and the native plant communities have been invaded by nonnative species, changes in vegetation structure and composition are likely to alter the fire regime. These changes, in turn, might alter the effects of fire on wildlife and wildlife habitat. In this paper, we develop a framework to evaluate whether fire and plant invasion act as independent, additive processes, or whether applying fire in invaded areas results in novel effects on wildlife. We explore changes in abundance of three small mammal species in response to experimental fires set along a gradient of dominance by Lehmann lovegrass (Eragrostis lehmanniana), an African bunchgrass that has invaded semidesert grasslands of the southwestern USA. For two of three species of small mammals, the effect of fire on abundance varied with the degree of invasion, suggesting a fire $\times$ invasion interaction. In systems dominated by nonnative plants, fire can function differently than it did prior to invasion, especially for animals with habitat requirements that match conditions created by the invading plant species. Consequently, prescriptions for restoration fires will need to consider the novel effects of fires on native plants and animals in areas where the plant community has changed.
\end{abstract}

Keywords: Eragrostis lehmanniana, fire, interactive effects, invasions, Lehmann lovegrass, nonnative species, small mammals

Citation: Steidl, R.J., and A.R. Litt. 2009. Do plant invasions change the effects of fire on animals? Fire Ecology 5(1): 56-66. doi: 10.4996/fireecology.0501056

\section{INTRODUCTION}

Grasslands are among the most endangered plant communities in North America, in part due to invasions by nonnative plants (Noss et al. 1995). Invasions alter the structure and composition of grassland plant communities by reducing heterogeneity and structural com- plexity, reducing space among plants, and often increasing biomass relative to native plant communities (Brooks et al. 2004, Geiger 2006). These alterations affect the ability of invaded areas to function as habitat for animals (D’Antonio and Vitousek 1992). Invasions by nonnative plants are thought primarily to reduce habitat quality for animals (Bock et al.

\footnotetext{
${ }^{1}$ Current address: Caesar Kleberg Wildlife Research Institute, Texas A\&M University-Kingsville, Kingsville, Texas 78363, USA
} 
1986), especially for species that prefer areas with high vegetation heterogeneity and lower biomass. For species that prefer lower vegetation heterogeneity and higher biomass, however, invasion can increase habitat quality (Litt 2007). Invasions by nonnative plants affect other aspects of invaded sites including changing the chemical composition and physical structure of soils, rates of soil erosion, and rates of water infiltration and runoff (Hendricks 1985, Kozlowski 1999, Dukes and Mooney 2004), each of which can affect animal populations (Rosenzweig and Winakur 1969, Morgan and Price 1992). Therefore, structural and functional changes resulting from plant invasions can affect the dynamics of animal populations and fire regimes on invaded sites (Mack and D'Antonio 1998, Brooks et al. 2004).

In grasslands, increases in plant biomass resulting from invasions increase the continuity and packing ratio of fuels (DeBano et al. 1998), which alter fire frequency, intensity, and severity (Brooks et al. 2004, McGlone and Huenneke 2004). Although species that inhabit fire-prone ecosystems have adaptations to cope with changes that fire brings to these areas, when nonnative plants become dominant components of a plant community, fire may function differently than before invasion. In systems dominated by nonnative plants, fire can operate outside of the natural range of variation, leading to novel conditions to which native animal species may not be adapted (D’Antonio et al. 1999) and that have the potential to drive local extirpation of species that cannot tolerate these altered fire regimes (Brooks et al. 2004).

Fire is being reestablished in many grassland systems in an attempt to restore these ecosystems by reducing dominance of nonnative plants (Geiger and McPherson 2005) and invading shrubs (McGlone and Huenneke 2004). Many grasslands, especially those in the southwestern US, have been invaded by fire-tolerant grasses (D’Antonio and Vitousek 1992) that respond positively to fire (Bock and Bock 1992). If novel fire regimes in these invaded ecosystems operate outside of the natural range of variation to which native organisms are adapted, the impacts of restoration and its effectiveness are uncertain.

Effects of fire on wildlife and wildlife habitat will depend on characteristics of the plant community and availability of fuels that affect the fire regime, including fire severity, frequency, and spatial extent. Severe fires that burn large areas uniformly eliminate much of the above-ground biomass, reducing habitat quality for species that rely on vegetation for cover and food (Smith 2000). In contrast, light, patchy surface fires that consume less above-ground biomass are likely to have lesser effects on habitat quality for animals.

Similarly, the effect of invasion by nonnative plants on habitat quality for animals depends on characteristics of the invading plant species, the degree of invasion, and the resulting contrast in structure and function of the invading plants relative to the native plants. Areas that become dominated by a single invading plant species tend to support lower levels of animal diversity relative to the native plant communities they replace. For animals, population abundance, community composition, and reproductive success may change in areas dominated by nonnative plants as a result of shifts in vegetation cover and structure (Slobodchikoff and Doyen 1977, Bock et al. 1986, Scheiman et al. 2003, Horncastle et al. 2005, Lloyd and Martin 2005, Flanders et al. 2006).

There is abundant evidence that animal populations are affected by both fire (e.g., Ream 1981, Smith 2000) and by invasions of nonnative plants (e.g., Slobodchikoff and Doyen 1977, Bock et al. 1986, Scheiman et al. 2003, Horncastle et al. 2005, Lloyd and Martin 2005, Flanders et al. 2006). What is less clear, however, is whether these two processes affect animal populations additively or wheth- 
er they function multiplicatively; that is, whether the effects of fire increase or decrease in intensity or change completely in areas invaded by nonnative plants relative to areas dominated by native plants. Before restoring fires, managers should know whether changes in structure and composition of the plant community due to invasions by nonnative plants alter the way that fire functions to affect animal populations and their habitats. We suggest that this question is addressed most appropriately as one of interaction: does the effect of fire vary with the degree of invasion by nonnative plants?

To explore the potential effects of fire on abundance of an animal population (or any other biological response variable) and whether the effects of fire depend on the degree of invasion, one could compute the net difference between burned and unburned (control) plots established across a gradient of nonnative plant invasion (Figure 1). If fire has no effect on the response, differences between burned and unburned plots would be zero (Figure 1a).

If differences in responses between burned and unburned plots were relatively consistent across the gradient of invasion, this would provide evidence of a simple (additive) effect of fire and therefore no evidence of a fire $\times$ invasion interaction, indicating that fire and plant invasion function independently (Figure 1a). If instead differences varied in magnitude and direction over the gradient of invasion, this would provide evidence of a fire-by-invasion interaction, indicating that fire and plant invasion function multiplicatively (Figure $1 b$ ).

We use this framework for assessing the effects of fire on animals inhabiting areas invaded by nonnative plants, and whether these two processes could interact to affect animals in synergistic ways that amount to more than the sum of their independent effects. We then explore how differences in dominance of nonnative plants affected responses of small mammal species to experimental fire in semidesert grasslands of the southwestern USA.

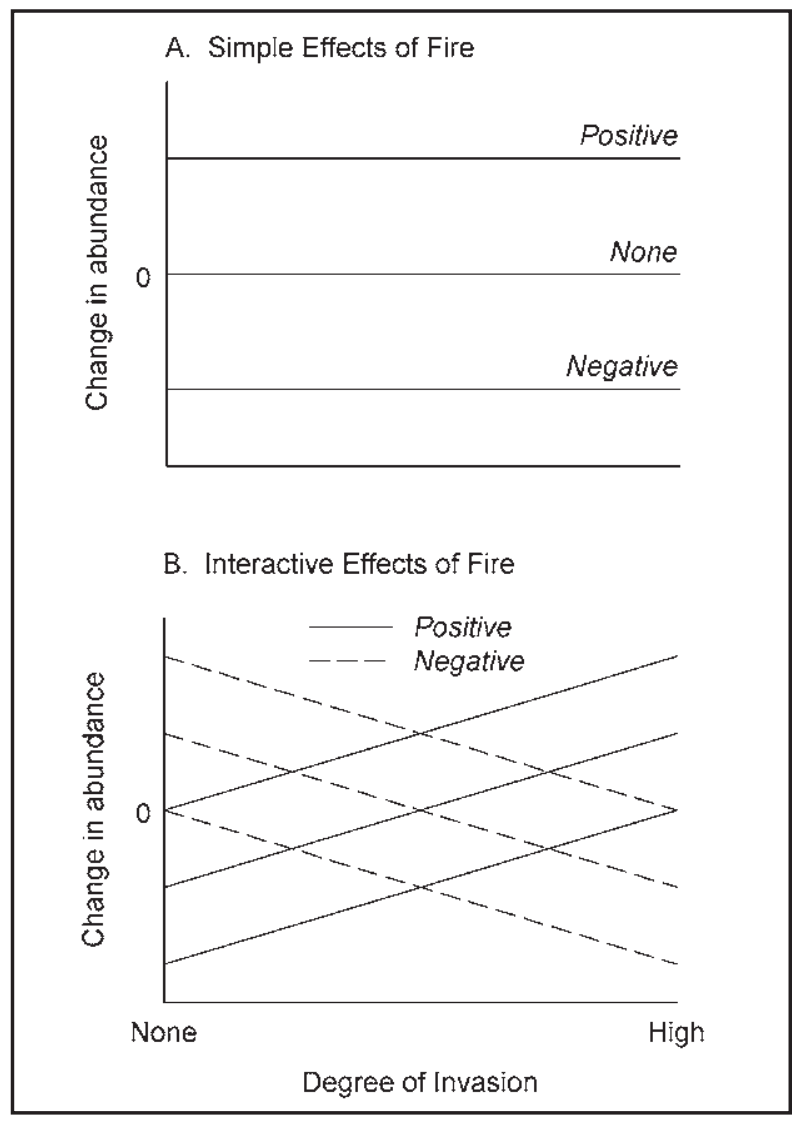

Figure 1. Potential responses of animal abundance in response to fire, including simple (additive) effects (A), where the effect of fire is independent of the degree of nonnative invasion, and a subset of potential interactive effects (B), where the effect of fire varies with the degree of nonnative grass invasion.

\section{METHODS}

\section{Study Area}

We studied semidesert grasslands and mesquite (Prosopis velutina) savannas in southeastern Arizona, at the base of the Huachuca Mountains on Fort Huachuca Military Reservation $\left(31^{\circ} 34^{\prime} \mathrm{N}, 110^{\circ} 26^{\prime} \mathrm{W}\right)$, at an elevation of approximately $1500 \mathrm{~m}$. Annual precipitation averages $391 \mathrm{~mm}(\mathrm{SE}=17 \mathrm{~mm}$, from 1955 through 1998), about two-thirds of which falls during the monsoon season between May and September, and one-third between October and April. The region is characterized by a hot, dry period between late March and early July prior to the onset of monsoon rain. His- 
torically, natural fires in these grasslands occurred about once every 10 years with their boundaries limited primarily by discontinuity of fine fuels (McPherson 1995). These fires were ignited by lightning coincident with the onset of the summer monsoon season when ambient temperatures were high and humidity and fuel moisture were low. Few livestock have grazed in this area since the late 1800 s, and livestock have been excluded completely since 1950. The most recent fires on the areas we studied occurred more than nine years before we initiated this study.

Our study area, like similar grasslands and savannas of the southwestern US, has been invaded by Lehmann lovegrass (Eragrostis lehmanniana), a nonnative perennial grass from South Africa planted in the 1930s (Crider 1945). Lehmann lovegrass produces more litter and up to four times more biomass than native grass species (Cable 1971, Anable et al. 1992) and has been associated with impacts on native plants and animals (Cable 1976, Bock et al. 1986, Geiger 2006). Lehmann lovegrass is well adapted to fire, with germination rates and dominance increasing after fire (Ruyle et al. 1988, Sumrall et al. 1991, Bock and Bock 1992). Common native plants included threeawn (Aristida spp.), cane blustem (Bothriochloa barbinodis), (Bouteloua spp.), crabgrass (Digitaria californica), plains lovegrass (Eragrostis intermedia), and panicgrass (Panicum spp.) (Geiger 2006).

Grasslands are especially suitable for our study because the plants are highly flammable, and the plant community is structurally simple, with less vertical structure and fewer fuel layers (ground, surface, and crown) than forests. Further, rapid elimination of aboveground plant biomass after fire is usually nearly complete (consumption of available fuels is commonly $>90 \%$ ), which simplifies assessing the effects of fire on animals. Plant recovery in grasslands is fairly rapid (Johnson 1997, Madden et al. 1999), so measuring recovery after fire is efficient.

\section{Experimental Design}

We designed a manipulative randomized experiment to assess the potential for a fire $\times$ invasion interaction by measuring the effects of fire on abundance of small mammals against a gradient of invasion by nonnative plants. We established nine pairs of 1 ha plots across a gradient where Lehmann lovegrass composed $0 \%$ to $91 \%$ of total live biomass (mean $=44.3$ $\%, \mathrm{SE}=4.9, n=18$ ). To maximize similarity between plots within a pair, we separated plots by $100 \mathrm{~m}$ to $200 \mathrm{~m}$, the minimum difference we felt necessary to ensure that animal populations on paired plots would be independent. We assigned the treatment (fire or control) to plots within each pair at random. Ignition of experimental fires was timed to coincide with the timing of historical lightning-ignited fires; all nine fires were completed within a four-day period in June 2001.

We used biomass $\left(\mathrm{g} \mathrm{m}^{-2}\right)$ of Lehmann lovegrass to characterize dominance of nonnative plants, which ranged from $0 \mathrm{~g} \mathrm{~m}^{-2}$ in areas not yet invaded up to $466 \mathrm{~g} \mathrm{~m}^{-2}$ in areas dominated by Lehmann lovegrass (Geiger 2006); our study plots spanned much of this gradient with biomass of Lehmann lovegrass ranging from $0 \mathrm{~g} \mathrm{~m}^{-2}$ to $333 \mathrm{~g} \mathrm{~m}^{-2}$. The difference in biomass of Lehmann lovegrass between plot pairs in the fall prior to fire averaged $48 \mathrm{~g} \mathrm{~m}^{-2}$ (95\% CI $=-8 \mathrm{~g} \mathrm{~m}^{-2}$ to $\left.102 \mathrm{~g} \mathrm{~m}^{-2}\right)$. All vegetation was clipped on $250.5 \mathrm{~m}^{2}$ quadrats on each plot each September from 1999 to 2003 . Samples were oven-dried and weighed by species for each quadrat, then averaged over all quadrats for each plot.

Prescription for fires involved burning a 10 $\mathrm{m}$ to $15 \mathrm{~m}$ strip around the outside of the plot perimeter, setting a head fire to burn the plot, followed by spot-ignition of any unburned patches to burn as much vegetation cover as possible. At ignition, air temperature averaged $31.8{ }^{\circ} \mathrm{C}$ (range $=27.8{ }^{\circ} \mathrm{C}$ to $35.0{ }^{\circ} \mathrm{C}$ ) and relative humidity averaged $14 \%$ (range $=2 \%$ to $26 \%$ ). Immediately after each fire, we mea- 
sured completeness of fire by walking two transects established diagonally across each plot and for each step we recorded whether the immediate area was burned or unburned, from which we computed the percentage of steps that were burned.

\section{Small Mammal Sampling}

We sampled small mammals during 12 sampling periods, three periods (one year) prior to treatment and nine periods (three years) following treatment. After an initial sampling period in summer 2000, we sampled regularly each winter (February through March), spring (May through June), and summer (July through August), through spring 2004. Within each sampling period, all plots were sampled within a span of three to four weeks. We used an $8 \times$ 8 grid of Sherman live traps spaced $12.5 \mathrm{~m}$ apart to sample small mammals on each plot. Traps were baited with wild bird seed and a mixture of peanut butter and oats, set at dusk, and checked at dawn every day for five consecutive days. We recorded species and body measurements from all animals captured. Animals were individually double-marked with a numbered ear tag and permanent felt-tipped markers, and animals were released at the site of capture. Animal-handing procedures were approved by the University of Arizona IACUC (protocols 99-121, 02-109).

We estimated abundance of Merriam's kangaroo rat (Dipodomys merriami), northern grasshopper mouse (Onychomys leucogaster), and Arizona cotton rat (Sigmodon arizonae) on each plot for each sampling period with closedcapture Huggins models using Program MARK (version 4.3, White and Burnham 1999). We selected these species because they inhabit the range of vegetation and environmental conditions represented in the study area and have life-history characteristics that offered potential to span the range of possible responses to the interaction between fire and de- gree of nonnative plant invasion. Abundance and richness of small mammals on these 1 ha plots was high (Litt 2007); for the three species we selected, for example, abundances reached maximums of 9 to 50 individuals per species per plot. We captured $94 \%$ of the 2822 individuals on only one plot during a sampling period, suggesting that plots were spaced sufficiently to function as independent experimental units. To increase the amount of information available for modeling detection probabilities, we aggregated data across plots for similar seasons for each species (Litt and Steidl in press). We considered candidate models for abundance estimation that included classification terms for year, fire treatment, and dominance of nonnative grass, and generated model-averaged estimates of abundance for each plot and each sampling period (Burnham and Anderson 2002).

\section{Statistical Analyses}

For each species, we quantified responses to fire as the difference in estimated abundance between pairs of burned and unburned plots using the log ratio of abundances (Törnqvist et al. 1985):

$$
\begin{aligned}
\log \text { ratio }= & \ln (\text { burn }+1) / \ln (\text { control }+1)= \\
& \ln (\text { burn }+1)-\ln (\text { control }+1)
\end{aligned}
$$

This metric is valuable because it accounts for inherent differences in abundance of each species across the gradient of nonnative grass invasion, which can confound questions of interaction.

We evaluated models that included the effects of degree of invasion, time since fire, and the interaction between the two. Because the response variable is the difference in abundance between burned and control pairs, the interactive effect of fire is implicit in each modeled effect. Therefore, a significant invasion effect indicates presence of a fire $\times$ inva- 
sion interaction. We quantified degree of invasion as average biomass of Lehmann lovegrass for each pair of plots for the two fall sampling periods prior to fire treatment (i.e., 1999 and 2000) and measured time since fire as the number of sampling periods after treatment, and treated both variables as continuous effects in our analysis. We included pre-treatment differences in abundance of small mammals between pairs of plots averaged across the three pre-fire sampling periods as a continuous covariate to account for inherent differences in abundance among plots.

We used a generalized linear mixed-model repeated-measures approach for analysis, treating plots as subjects to account for repeated measurements taken from the same plots over time (Littell et al. 2006). We considered four possible covariance structures for these models and selected the first-order autoregressive structure because it had the smallest $\mathrm{AIC}_{\mathrm{c}}$ and $\mathrm{BIC}$ values for all species.

\section{RESULTS}

Fuel load (total plant biomass) on plots prior to fire ignition averaged $313 \mathrm{~g} \mathrm{~m}^{-2}(\mathrm{SE}=$ 36.5 , range $=62 \mathrm{~g} \mathrm{~m}^{-2}$ to $437 \mathrm{~g} \mathrm{~m}^{-2}$ ), fuel moisture averaged $18 \%(\mathrm{SE}=1.7$, range $=13$ to $25)$, and fires burned an average of $95 \%(\mathrm{SE}=$ 1.9 , range $=84 \%$ to $100 \%$ ) of vegetation on plots. There was no relationship between burn completeness and biomass of Lehmann lovegrass $\left(t_{8}=-1.5, P=0.19\right)$, total plant biomass $\left(t_{8}\right.$ $=0.8, P=0.47)$, or fuel moisture $\left(t_{8}=0.3, P=\right.$ 0.77 , likely because burns were almost uniformly complete.

Fire affected abundance of all three species of small mammals. For two of the three, the effect of fire on abundance varied with the degree of nonnative plant invasion (Table 1, Figure 2). Relative to unburned controls, abundance of Merriam's kangaroo rat increased after fire and did so relatively consistently across the gradient of nonnative plant invasion $(P=$ 0.87 for fire $\times$ invasion interaction). In contrast, for both northern grasshopper mouse and Arizona cotton rat, the effects of fire on abundance varied with the degree of nonnative grass invasion. Abundance of northern grasshopper mouse showed evidence of a slight positive interaction in response to fire and degree of nonnative plant invasion (Table 1) as both the direction and magnitude of fire effects changed across the gradient of invasion. After fire, abundance of northern grasshopper mouse decreased in areas dominated by native grass and increased in areas dominated by nonnative grass (Figure 2).

Abundance of Arizona cotton rat showed evidence of a strong negative interaction in response to fire and degree of nonnative invasion (Table 1). In contrast to northern grasshopper mouse, abundance of Arizona cotton rat almost

Table 1. Factors assessing differences in abundance ${ }^{a}$ of small mammals between burned and control plots ( $n=9$ plot-pairs) in southeastern Arizona, 2000-2004. The term "invasion" represents the biomass of nonnative grass on plots and "time-since-fire" represents the number of sampling periods (1-9) after fire.

\begin{tabular}{lcccccc}
\hline & \multicolumn{3}{c}{ Dipodomys merriami } & \multicolumn{2}{c}{ Onychomys leucogaster } & \multicolumn{2}{c}{ Sigmodon arizonae } \\
\cline { 2 - 7 } Factors & $\boldsymbol{F}^{\text {a }}$ & $\boldsymbol{P}$ & $\boldsymbol{F}$ & $\boldsymbol{P}$ & $\boldsymbol{F}$ & $\boldsymbol{P}$ \\
\hline Fire $\times$ Invasion & 0.03 & 0.87 & 5.86 & 0.052 & 13.16 & 0.011 \\
Fire $\times$ Time-since-fire & 1.70 & 0.20 & 0.51 & 0.48 & 0.75 & 0.39 \\
Fire $\times$ Invasion $\times$ Time-since-fire & 1.14 & 0.29 & 1.49 & 0.23 & 3.32 & 0.073 \\
Pre-treatment abundance & 0.56 & 0.48 & 6.73 & 0.041 & 3.25 & 0.12 \\
\hline${ }^{\mathrm{a}} F$-statistics have 70 denominator degrees of freedom for tests that include time-since-fire and 6 degrees of freedom \\
$\quad$ for all other tests. \\
${ }^{\mathrm{b}}$ Included as a covariate to account for inherent differences in abundance among plots.
\end{tabular}




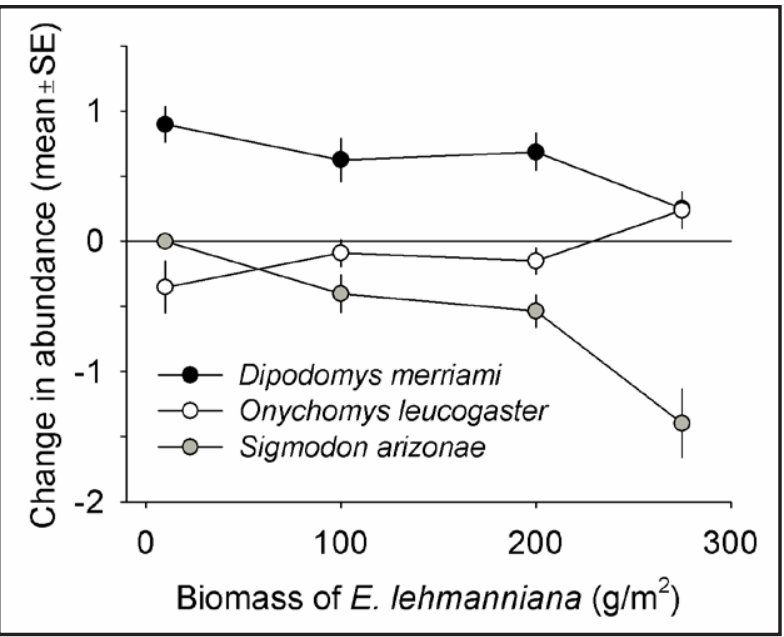

Figure 2. Difference in abundance between burned and control plots (log ratio) for three small mammal species versus degree of nonnative invasion averaged across all three years of post-fire sampling, southern Arizona, 2000 to 2004.

always decreased after fire; however, the magnitude of the decrease was greatest in areas where nonnative invasion was highest (Figure 2). During the three years after fire, abundances of Merriam's kangaroo rat and northern grasshopper mouse remained relatively consistent over time (Table 1), whereas abundance of Arizona cotton rat increased systematically over time, approaching unburned levels about three years after fire (Figure 3).

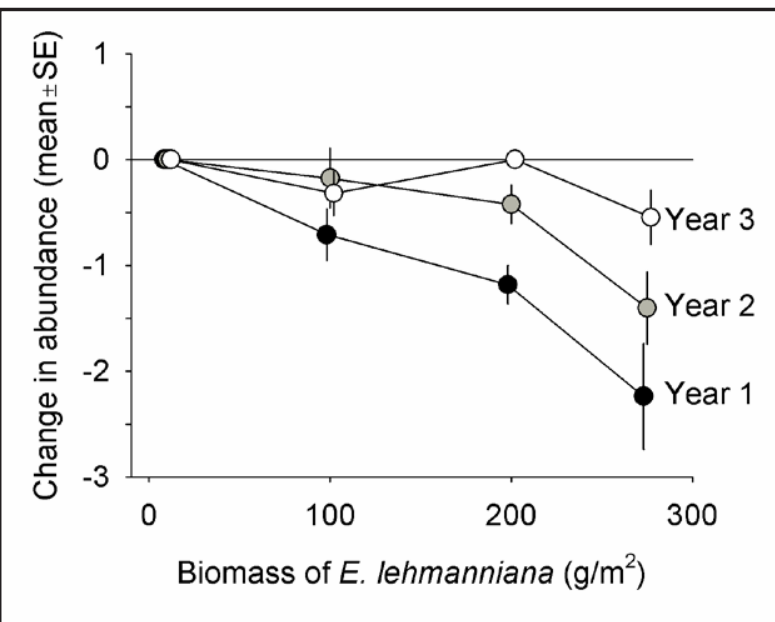

Figure 3. Difference in abundance between burned and control plots (log ratio) for Sigmodon arizonae versus degree of nonnative invasion for three years after fire, southern Arizona, 2000 to 2004.

\section{DISCUSSION}

The effects of fire on abundance of some small mammals varied with the degree to which the native plant community was invaded by nonnative species (Table 1, Figure 2), indicating that fire functions differently in grasslands invaded by nonnative plants relative to native grasslands. The magnitude of fire $\times$ invasion interaction varied by species, which suggests more broadly that the presence and magnitude of this interaction is likely to depend on the suite of species inhabiting a site, the physical differences between the invading plant species and the native plant species being replaced, and the overall degree of invasion.

The species of small mammals we examined illustrate nearly the full range of potential responses to the fire $x$ invasion interaction (Figure 1). We observed the strongest interaction for Arizona cotton rat, a species that reaches its highest abundance in areas of high vegetation cover and structure (Hoffmeister 1986, Bowers and Flanagan 1988, Brown and Heske 1990, Litt 2007). In contrast, we detected no interaction for Merriam's kangaroo rat, a species that is most abundant in areas of sparse vegetation cover (Brown and Heske 1990). We observed a moderate interaction for northern grasshopper mouse, a species that inhabits areas of intermediate vegetation cover (Litt 2007). Therefore, the degree to which the function of fire changed in response to plant invasion depended on the degree to which the dominant nonnative plant provided vegetation conditions that these small mammal species prefer as habitat.

For animals that inhabit areas of high vegetation density - the condition created most commonly by nonnative grasses that have invaded this region-elimination of vegetation by fire is likely to reduce habitat quality for these species the most (Bock and Bock 1978, Lyon et al. 2000). For animals that prefer areas of low vegetation density, any fire that 
eliminates most of the vegetation on a site should improve habitat quality. For these species, whether the vegetation on a site before fire was native or nonnative should make little difference, as habitat quality should increase in the short term if other important habitat features are present. This likely explains why we observed no fire $x$ invasion interaction for Merriam's kangaroo rat. Overall, in systems dominated by nonnative plants, fire can function differently than it did prior to invasion, especially for those animals with habitat requirements that match the conditions created by the invading plant species.

Although elimination of vegetation structure after fire may be the dominant process affecting habitat quality for animals, plant invasions could also change the way that fire affects other factors that could influence the strength of the fire $\times$ invasion interaction, such as species-specific differences in diet. For example, the diet of northern grasshopper mouse consists mainly of invertebrates (Hoffmeister 1986), the abundance of which increases in response to the growth of new vegetation stimulated by fire (Warren et al. 1987; Bond and van Wilgren 1996; Milller 2000; Andrea Litt, University of Arizona, unpublished data). If growth of vegetation after fire occurs more rapidly in invaded areas, resulting in a similar increase in invertebrates, this could contribute to variation in abundance of this small mammal species across the invasion gradient.

We found that restoring fires to invaded grasslands ecosystems can have novel effects on ecosystem structure and function. The intensity of these effects will depend on differences between the invading plants and native plants, how these differences alter the fire regime relative to historic conditions, and the structure and composition of the native plant community. Because many perennial nonnative plant species invading grasslands have higher plant densities and higher biomass than native species (Brooks et al. 2004, Geiger 2006), fuel loadings and fuel continuity can be higher in invaded systems, resulting in increased fire frequency and severity. Because one likely consequence of global climate change is an increase in the propensity of successful invasions by nonnative plant species (Dukes and Mooney 1999), invasions by nonnative plants are likely to increase in frequency and geographic scope, exacerbating functional differences in fire between native- and nonnative-dominated grasslands, at least so far as effects on habitat for native animals are concerned. This suggests that managers and researchers should consider carefully the effects of restoring fire in altered ecosystems before committing to full-scale restoration efforts.

Although fire functioned differently in the invaded grasslands we studied, restoring fire is important to stimulate other important ecosystem functions, such as nutrient cycling, primary productivity, and seed germination, and to maintain a heterogeneous vegetation mosaic across the landscape (Hobbs and Huenneke 1992, Steuter and McPherson 1995, Bond and van Wilgren 1996, Miller 2000). Ultimately, managers will need to choose between maintaining a natural fire regime and altering fire regimes to favor communities of native species (Keeley 2006), despite potentially adverse effects on some ecosystem components. In grassland ecosystems, however, post-fire recovery is relatively rapid (Smith 2000, Litt 2007, Figure 3), therefore adverse effects to native species may not persist over long time periods. 


\section{ACKNOWLEDGEMENTS}

We appreciate contributions to many aspects of this work by E.L. Geiger, G.R. McPherson, and S. Stone, as well as the help of our field assistants, too numerous to mention. We thank P. Bidegain and the dedicated crew from Fort Huachuca Fire Station No. 2 who ensured that all of the fires we proposed were set in a timely, safe, and professional manner. Our research was supported by the Department of Defense Legacy Resource Management Program and the University of Arizona Agricultural Experiment Station. Our manuscript has benefited from constructive comments provided by two anonymous reviewers.

\section{LITERATURE CITED}

Anable, M.E., M.P. McClaran, and G.B. Ruyle. 1992. Spread of introduced Lehmann lovegrass Eragrostis lehmanniana Nees in southern Arizona, USA. Biological Conservation 61: 181188.

Bock, C.E., and J.H. Bock. 1978. Response of birds, small mammals, and vegetation to burning sacaton grasslands in southeastern Arizona. Journal of Range Management 31: 296-300.

Bock, C.E., J.H. Bock, K.L. Jepson, and J.C. Ortega. 1986. Ecological effects of planting African lovegrasses in Arizona. National Geographic Research 2: 456-463.

Bock, J.H., and C.E. Bock. 1992. Vegetation responses to wildfire in native versus exotic Arizona grassland. Journal of Vegetation Science 3: 439-446.

Bond, W.J., and B.W. van Wilgren. 1996. Fire and plants. Chapman and Hall, London, United Kingdom.

Bowers, M.A., and C.A. Flanagan. 1988. Microhabitat as a template for the organization of a desert rodent community. Pages 300-312 in: R.C. Szaro, K.E. Severson, and D.R. Patton, editors. Management of amphibians, reptiles, and small mammals in North America. USDA Forest Service General Technical Report RM-166.

Brooks, M.L., C.M. D’Antonio, D.M. Richardson, J.B. Grace, J.E. Keeley, J.M. DiTomaso, R.J. Hobbs, M. Pellant, and D. Pyke. 2004. Effects of invasive alien plants on fire regimes. Bioscience 54: 677-688.

Brown, J.H., and E.J. Heske. 1990. Control of a desert-grassland transition by a keystone rodent guild. Science 250: 1705-1707.

Burnham, K.P., and D.R. Anderson. 2002. Model selection and inference: a practical informationtheoretic approach, Second edition. Springer, New York, New York, USA.

Cable, D.R. 1971. Lehmann lovegrass on the Santa Rita experimental range, 1937-1968. Journal of Range Management 24: 17-21.

Cable, D.R. 1976. Twenty years of changes in grass production following mesquite control and reseeding. Journal of Range Management 29: 286-289.

Crider, F.J. 1945. Three introduced lovegrasses for soil conservation. US Department of Agriculture Circular 730.

D’Antonio, C.M., and P.M. Vitousek. 1992. Biological invasions by exotic grasses, the grass/fire cycle, and global change. Annual Review of Ecology and Systematics 23: 63-87.

D’Antonio, C.M., T.I. Dudley, and M. Mack. 1999. Disturbance and biological invasions: direct effect and feedbacks. Pages 143-152 in: L.R. Walker, editor. Ecosystems of disturbed ground. Elsevier, Amsterdam, Netherlands. 
DeBano, L.F., D.G. Neary, and P.F. Ffolliott. 1998. Fire's effects on ecosystems. John Wiley and Sons, New York, New York, USA.

Dukes, J.S., and H.A. Mooney. 1999. Does global change increase the success of biological invaders? Trends in Ecology and Evolution 14: 135-139.

Dukes, J.S., and H.A. Mooney. 2004. Disruption of ecosystem processes in western North America by invasive species. Revista Chilena de Historia Natural 77: 411-437.

Flanders, A.A., W.P. Kuvlesky, Jr., D.C. Ruthven, III, R.E. Zaiglin, R.L. Bingham, T.E Fulbright, F. Hernandez, and L.A. Brennan. 2006. Effects of invasive exotic grasses on south Texas rangeland breeding birds. The Auk 123: 171-182.

Geiger, E.L. 2006. The role of fire and a nonnative grass as disturbances in semi-desert grasslands of southeastern Arizona. Dissertation, University of Arizona, Tucson, USA.

Geiger, E.L., and G.R. McPherson. 2005. Response of semi-desert grasslands invaded by nonnative grasses to altered disturbance regimes. Journal of Biogeography 32: 895-902.

Hendricks, D.M. 1985. Arizona soils. College of Agriculture, University of Arizona, Tucson, USA.

Hobbs, R.J., and L.F. Huenneke. 1992. Disturbance, diversity, and invasion: implications for conservation. Conservation Biology 6: 324-337.

Hoffmeister, D.F. 1986. Mammals of Arizona. University of Arizona Press, Tucson, USA.

Horncastle, V.J., E.C. Hellgren, P.M. Mayer, A.C. Ganguli, D.M. Engle, and D.M. Leslie, Jr. 2005. Implications of invasion by Juniperus virginiana on small mammals in the southern Great Plains. Journal of Mammalogy 86: 1144-1155.

Johnson, D.H. 1997. Effects of fire on bird populations in mixed-grass prairie. Pages 181-206 in: F.L. Knopf and F.B. Samson, editors. Ecology and conservation of Great Plains vertebrates. Ecological Studies Volume 125. Springer Verlag, New York, New York, USA.

Keeley, J.E. 2006. Fire management impacts on invasive plants in the western United States. Conservation Biology 20: 375-384.

Kozlowski, T.T. 1999. Soil compaction and growth of woody plants. Scandinavian Journal of Forest Research 14: 596-619.

Litt, A.R. 2007. Effects of experimental fire and nonnative grass invasion on small mammals and insects. Dissertation, University of Arizona, Tucson, USA.

Litt, A.R. and R.J. Steidl. In press. Improving estimates of abundance by aggregating sparse capture-recapture data. Journal of Agricultural, Biological, and Environmental Statistics.

Littell, R.C., G.A. Milliken, W.W. Stroup, R.D. Wolfinger, and O. Schabenberber. 2006. SAS for mixed models, second edition. SAS Press, Cary, North Carolina, USA.

Lloyd, J.D., and T.E. Martin. 2005. Reproductive success of chestnut-collared longspurs in native and exotic grassland. The Condor 107: 363-374.

Lyon, L.J., M.H. Huff, E.S. Telfer, D.S. Schreiner, and J.K. Smith. 2000. Fire effects on animal populations. Pages 25-34 in: J.K. Smith, editor. Wildland fire in ecosystems: effects of fire on fauna. USDA Forest Service General Technical Report RMRS-GTR-42-volume 1.

Mack, M.C., and C.M. D’Antonio. 1998. Impacts of biological invasions on disturbance regimes. Trends in Ecology and Evolution 13: 195-198.

Madden, E.M., A.J. Hansen, and R.K. Murphy. 1999. Influence of prescribed fire history on habitat and abundance of passerine birds in northern mixed-grass prairie. Canadian FieldNaturalist 113: 627-640. 
McPherson, G.R. 1995. The role of fire in the desert grasslands. Pages 130-151 in: M.P. McClaran and T.R. Van Devender, editors. The desert grassland. The University of Arizona Press, Tucson, USA.

McGlone, C.M., and L.F. Huenneke. 2004. The impact of a prescribed fire on introduced Lehmann lovegrass versus native vegetation in the northern Chihuahuan Desert. Journal of Arid Environments 57: 297-310.

Miller, M. 2000. Fire autecology. Pages 9-34 in: J.K. Brown and J.K. Smith, editors. Wildland fire in ecosystems: effects of fire on flora. USDA Forest Service General Technical Report RMRS-GTR-42-volume 2.

Morgan, K.R., and M.V. Price. 1992. Foraging in heteromyid rodents: the energy cost of scratchdigging. Ecology 73: 2260-2272.

Noss, R.F., E.T. LaRoe, and J.M. Scott. 1995. Endangered ecosystems of the United States: a preliminary assessment of loss and degradation. US Department of Interior, National Biological Service, Washington, D.C., USA.

Ream, C.H. 1981. The effects of fire and other disturbances on small mammals and their predators: an annotated bibliography. USDA Forest Service General Technical Report INT-106.

Rosenzweig, M.L., and J. Winakur. 1969. Population ecology of desert rodent communities: habitats and environmental complexity. Ecology 50: 558-572.

Ruyle, G.B., B.A. Roundy, and J.R. Cox. 1988. Effects of burning on germinability of Lehmann lovegrass. Journal of Range Management 41: 404-406.

Scheiman, D.M., E.K. Bollinger, and D.H. Johnson. 2003. Effects of leafy spurge infestation on grassland birds. Journal of Wildlife Management 67: 115-121.

Slobodchikoff, C.N., and J.T. Doyen. 1977. Effects of Ammophila arenaria on sand dune arthropod communities. Ecology 58: 1171-1175.

Smith, J.K., editor. 2000. Wildland fire in ecosystems: effects of fire on fauna. USDA Forest Service General Technical Report RMRS-GTR-42-volume 1.

Steuter, A.A., and G.R. McPherson. 1995. Fire as a physical stress. Pages 550-579 in: D.J. Bedunah and R.E. Sosebee, editors. Wildland plants: physiological ecology and developmental morphology. Society for Range Management, Denver, Colorado, USA.

Sumrall, L.B., B.A. Roundy, J.R. Cox, and V.K. Winkel. 1991. Influence of canopy removal by burning or clipping on emergence of Eragrostis lehmanniana seedlings. International Journal of Wildland Fire 1: 35-40.

Törnqvuist, L., P. Vartia, and Y.O. Vartia. 1985. How should relative changes be measured? The American Statistician 39: 43-46.

Vitousek, P.M., C.M. D’Antonio, L.L. Loope, and R. Westbrooks. 1996. Biological invasions as global environmental change. American Scientist 84: 468-478.

Warren, S.D., C.J. Scifres, and P.D. Teel. 1987. Response of grassland arthropods to burning: a review. Agriculture, Ecosystems, and Environment 19: 105-130.

White, G.C., and K.P. Burnham. 1999. Program MARK: survival estimation from populations of marked animals. Bird Study 46 Supplement: 120-138. 